\title{
ANALISIS WIRELESS POWER TRANSMISSION SYSTEM DALAM ASPEK REGULASI MENGGUNAKAN METODE BENCHMARK
}

\author{
Samsurizal \\ Jurusan Teknik Elektro, Sekolah Tinggi Teknik - PLN \\ Email: samsurizal@sttpln.ac.id
}

\begin{abstract}
Wireless technology has developed very rapidly both in terms of providing infrastructure and supporting technology that is on the side of the mobile computing device that has been widely used by people. Charging the battery is one of the primary needs of modern society. To support community activities that the higher the level of mobility, power bank is a solution. However, the ability of power banks are still limited in terms of charging. Thus, the wireless charging technology, or better known as the Wireless Power Transmission (WPT). Wireless Power Transmission is a technology that allows electrical energy from the power source to an electrical load is transmitted without any interconnection. Wireless Power Transmission especially useful for devices connected to the cable dangerous. This is new technology but the market has seen demand increase significantly. Various types of applications, that the technology Wireless Power Transmission (WPT) is applied, the expected and the study of the current WPT is underway. Also, ongoing standardization activities in several standardization organizations.as well as the issuance of Wireless Power Transmission Regulations in some countries so expect the harmonization of rules / law in the implementation of Wireless Power Transmission in everyday life, Clarity and certainty of legal framework for the implementation of the regulatory function of the business operations of Wireless Power Transmission.
\end{abstract}

Keywords: WPT, Regulation, Standardization.

\begin{abstract}
ABSTRAK
Teknologi wireless telah berkembang sangat pesat baik dalam hal penyediaan infrastruktur maupun teknologi pendukungnya yaitu dari sisi perangkat komputasi bergerak yang telah banyak digunakan oleh masyarakat. Charging baterai merupakan salah satu kebutuhan primer dari masyarakat modern. Untuk mendukung aktivitas-aktivitas masyarakat yang semakin tinggi tingkat mobilitasnya, power bank merupakan solusi. Namun, kemampuan power bank masih terbatas dalam hal charging. Sehingga, teknologi charging tanpa kabel atau yang lebih dikenal dengan Wireless Power Transmission (WPT). Wireless Power Transmision adalah teknologi yang memungkinkan energi listrik dari sumber listrik ke beban listrik ditransmisikan tanpa interkoneksi. Wireless Power Transmision berguna terutama pada perangkat yang terhubung dengan kabel yang berbahaya. Ini adalah teknologi baru tapi permintaan pasar sudah terlihat meningkat secara signifikan. Berbagai jenis aplikasi, bahwa teknologi Wireless Power Transmision (WPT) diterapkan, yang diharapkan dan studi tentang WPT yang aktif sedang berlangsung. Juga, kegiatan standardisasi yang berlangsung di beberapa organisasi standardisasi. serta diterbitkannya Regulasi Wireless Power Transmission di beberapa negara sehingga diharapkan adanya harmonisasi aturan / Undang-Undang dalam penyelenggaraan Wireless Power Transmission dalam kehidupan sehari-hari, Kejelasan dan kepastian payung hukum fungsi pengaturan terhadap penyelenggaraan operasi bisnis Wireless Power Transmission.
\end{abstract}

Kata Kunci: WPT, Regulasi, Standardisasi. 


\section{PENDAHULUAN}

\subsection{Latar Belakang Masalah}

Salah satu isu utama dalam sistem tenaga adalah kerugian yang terjadi selama transmisi dan distribusi tenaga listrik. Permintaan tenga listrik akan meningkat dari hari ke hari, pembangkit listrik juga meningkat dan daya yang hilang juga meningkat. Besarnya daya yang hilang selama transmisi dan distribusi diperkirakan sebesar 26\%. Alasan utama untuk kehilangan power selama transmisi dan distribusi adalah resistansi kabel yang digunakan untuk jaringan. Efisiensi transmisi daya dapat ditingkatkan untuk tingkat tertentu dengan menggunakan komposit kekuatan tinggi lebih dari kondktor dan kabel bawah tanah yang menggunakan suhu tinggi yang super konduktor. Tapi, transmisi masih tidak efisien. Menurut World Resources Institute (WRI), jaringan listrik India memiliki kerugian transmisi dan distribusi tertinggi didunia-kerugian hingga 27\%. Angka-angka yang diterbitkan oleh berbagai instansi pemerintah India menempatkan jumlah sebesar 30\%, 40\% dan lebih besar dari $40 \%$. Hal ini disebabkan kerugian teknis (inefisiensi grid) dan pencurian.

Teknologi nirkabel telah berkembang secara pesat lebih dari dua decade terakhir, baik dalam hal penyediaan infrastruktur maupun teknologi pendukungnya yaitu dari sisi perangkat komputasi bergerak yang telah banyak digunakan oleh masyarakat. Handphone merupakan perangkat telekomunikasi wireless yang menjadi kebutuhan vital dalam kehidupan masyarakat modern. Saat ini fitur-fitur yang tersedia pada piranti-piranti komputasi bergerak tersedia luas dalam pasar lokal dan sangat mendukung bervariasinya aktivitas sehari-hari, seperti untuk apikasi medis, bisnis, edukasi dan lain sebagainya.

Charging baterai merupakan salah satu kebutuhan primer dari masyarakat modern. Untuk mendukung aktivitas-aktivitas masyarakat yang semakin tinggi tingkat mobilitasnya, power bank merupakan solusi. Namun, kemampuan power bank masih terbatas dalam hal charging. Sehingga teknologi charging tanpa kabel atau yang lebih dikenal dengan Wireless Power Transmission (WPT). Sistem WPT yang digabungkan dengan sumber-sumber energi terbarukan lainnya yang sangat ramah lingkungan seperti cahaya matahari, energi panas (kalor), energi getaran dan lain sebagainya memiliki prospek yang sangat menarik untuk dikaji dan dikembangkan. Teknologi WPT tentunya akan sangat membantu dalam hal charging piranti komputasi bergerak dan juga akan menjadi lebih efektif serta efisien karena dapat mengisi ulang lebih dari satu piranti komputasi bergerak dalam suatu waktu bersamaan tanpa harus menggunakan kabel lagi yang terkoneksi ke sumber listrik.

Wireless charging, juga dikenal sebagai Transfer Daya Nirkabel adalah teknologi yang memungkinkan sumber daya untuk memancarkan energi elektromagnetik ke beban listrik di celah udara tanpa interkoneksi kabel. Saat ini, pengisian nirkabel cepat berkembang dari teori menuju fitur standar pada produk komersial, khususnya ponsel dan perangkat pintar portabel. Pada tahun 2014, banyak produsen smartphone terkemuka, seperti Samsung, Apple dan Huawei, mulai melepaskan perangkat generasi baru dengan fitur built-in kemampuan pengisian nirkabel. IMS Research membayangkan bahwa pasar pengisian nirkabel menjadi 4.5 miliar pada tahun 2016. Pike Research memperkirakan bahwa produk bertenaga nirkabel akan tiga kali lipat pada tahun 2020 menjadi 15 miliar.

Wireless Power Transfer mulai melihat penerimaan yang luas dalam banyak aplikasi. Integrasi WPT ke dalam perangkat mobile dan konsumen elektronik telah mengambil bentuk melalui standarisasi pada skala dunia. Teknologi ini memungkinkan plug bebas dan dalam banyak kasus, contactless pengisian untuk berbagai perangkat dan mesin. Berasal dari mekanisme pengisian induktif sederhana yang memerlukan titik lanngsung kontak antara charger (transmitter) dan perangkat (receiver), sistem ini telah berkembang ke titik memberikan kecerdasan yang akan melihat perangkat menjadi terhubung ke infrastruktur listrik yang lebih luas.

Pike Research percaya bahwa adopsi WPT pengisian dan transmisi perangkat, terutama untuk perangkat mobile, CE dan EVS akan terus naik selama 5 tahun kedepan dan akan lebih cepat lagi karena harga nya murah dan sistem WPT diintegrasikan ke dalam kehidupan sehari-hari. Bebrapa faktor menonjol seperti persepsi publik dan isu-isu regulasi serta keselamatan bisa menunda adopsi tetapi mereka kemungkinan akan sebanding dengan kenyamanan dan kesederhanaan sistem WPT. 


\subsection{Tujuan Penelitian}

Tujuan yang hendak di capai dari dalam tulisan ini adalah

1. Menganalisa dari sisi frekuensi dan aplikasi operasional Wireless Power Transmission di Indonesia.

2. Merumuskan regulasi Wireless Power Transmission untuk dapat diterapkan di Indonesia

\subsection{Landasan Teori}

Nikola Tesla adalah orang yang pertama kali menyusun ide tentang wireless power transmission dan menunjukkan "transmisi energi listrik tanpa kabel" yang tergantung pada konduktivitas listrik.Pada tahun 1893, Tesla mendemonstrasikan pencahayaan dari lampu vakum tanpa menggunakan kabel untuk transmisi listrik di Dunia Exposition Columbian di Chicago.Pada tahun 1904, motor kapal kapal udara dari 0.1 Horse Power didorong oleh kekuatan transmisi melalui ruang dari kejauhan dari setidaknya 100 kaki. Pada tahun 1961, Brown menerbitkan makalah pertama mengusulkan energi gelombag mikro untuk transmisi listrik, dan pada tahun 1964 ia menunjukkan sebuah model helicopter bertenaga microwave yang menerima semua daya yang dibutuhkan untuk penerbangan dari sinar microwave di $2,45 \mathrm{GHz}$ dari kisaran 2,4 GHz-pita frekuensi 2,5 GHz.

Pada tahun 2003, pesawat Dryden Pusat Penelitian NASA menunjukkan laser bertenaga model pesawat didalam ruangan. Jepang mengusulkan charging nirkabel kendaraan motor listrik dengan Microwave Transmisi Power pada tahun 2004. Powercast, sebuah perusahaan yang memperkenalkan teknologi wireless power transmision menggunakan RF pada tahun 2007. Sebuah kelompok riset fisika, yang dipimpin oleh Prof. Marin Soljcacic, di Massachusetts Institute of Technology (MIT) menunjukkan powering nirkabel dari bola lampu $60 \mathrm{~W}$ dengan efisiensi $40 \%$ pada jarak 2 meter menggunakan dua gulungan berdiameter $60 \mathrm{~cm}$ pada tahun 2007. Baru-baru ini pada tahun 2008, Intel memproduksi percobaan dari kelompok MIT yaitu menyalakan bola lampu dengan efisiensi $75 \%$ pada jarak yang lebih pendek.

Wireless Power Transmision telah diterapkan untuk waktu yang lama di transformator dimana kumparan primer dan sekunder erat digabungkan, misalnya dengan menggunakan magnet inti permeabel bersama. Transfer daya induktif melalui udara dengan kumparan primer dan sekunder secara fisik terpisah. Masalah mendasar dalam teknologi ini adalah bahwa efisiensi transfer daya menurun secara dramatis jika jarak melalui udara lebih besar dari diameter kumparan. Efisiensi dari transfer daya tergantung pada faktor coupling $(\mathrm{k})$ antara induktor dan kualitas mereka $(\mathrm{Q})$. Teknologi ini telah dikomersilkan untuk 1:1 pengisian ponsel pintar. Dengan array kumparan, teknologi ini juga menawarkan fleksibilitas dalam lokasi penerima kumparan pemancar.

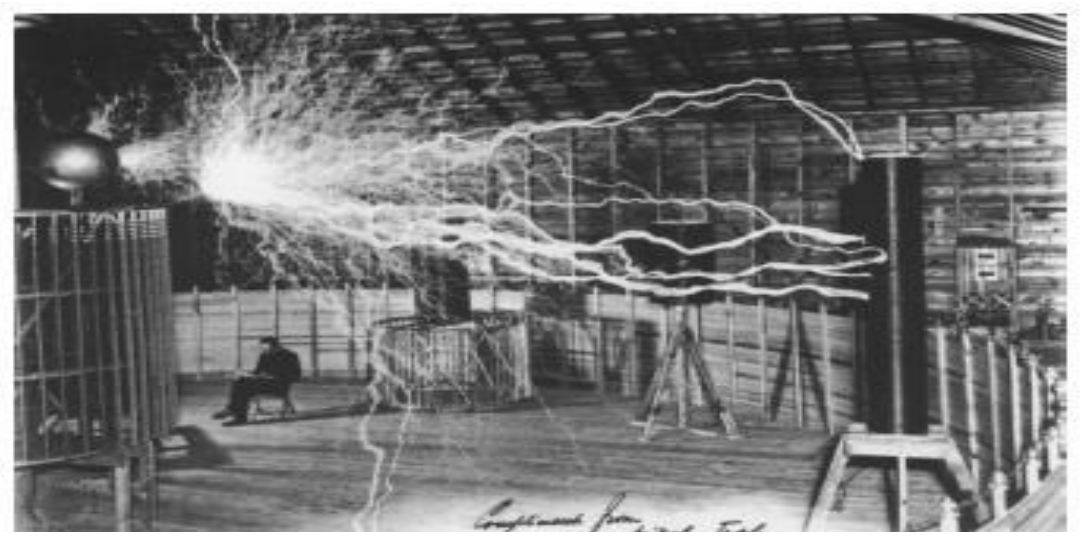

Gambar 1. Penelitian transmis energi listrik tanpa kabel yang dilakukan Nikola Tesla 


\section{METODE PENELITIAN}

\subsection{Metode Penelitian}

Pada penelitian ini menggunakan pendekatan penelitian kualitatif, dengan metode Benchmark. Dimana metode benchmark adalah salah satu kegiatan yang dilakukan sebuah organisasi atau instansi untuk mengetahui kinerja yang telah dicapai serta dapat meningkatkan kinerja tersebut. Kegiatan ini dilakukan dengan membandingkan proses-proses dan praktek kerja yang ada dengan organisasi atau institusi lain yang memiliki proses kerja yang sama. Dari kegiatan ini, organisasi dapat belajar dari organisas lain yang serupa, mengetahui kekurangan dan kelebihan dari organisasi masing-masing sehingga dapat dijadikan sebagai perbaikan dan peningkatan kinerja. Sebelum melakukan benchmarking, organisasi atau institusi harus terlebih dahulu mengetahui dan mengerti kondisi kinerja internalnya sehingga nanti nya dapat mengukur keberhasilan kinerja organisasi selama ini jika dibandingkan dengan organisasi serupa. Benchmarking tidak hanya secara eksternal saja, tetapi juga dapat dilakukan secara internal dengan membandingkan unit-unit didalam organisasi.

\subsection{Metode Pengumpulan Data}

Untuk mendapatkan data-data yang dibutuhkan, maka peneliti menggabungkan beberapa metode pengumpulan data yang antara lain:

a. Pengumpulan Data

Pengumpulan data-data pendukung pada penelitian ini diambil dari APT Wireless Group

(AWG), ITU dan data perkembangan telekomunikasi terakhir negara-negara sampel.

b. Dokumentasi

Dokumentasi dalam hal ini merupakan data sekunder berupa: struktur organisasi, anual report, foto, data di server dan website, dalam hal ini penulis bisa memperoleh informasi-informasi yang dibutuhkan.

c. Wawancara (Interview)

Peneliti melakukan wawancara dengan pihak terkait dengan Teknik wawancara mendalam. Tanya jawab secara bertatap muka langsung dengan orang yang di wawancarai, menggunakan pedoman wawancara secara khusus tentang kondisi terkini regulasi Wireless Power Transmission di Indonesia.

\section{HASIL DAN ANALISIS}

\subsection{Identifikasi Regulasi Wireless Power Transmission}

Tujuan yang hendak dicapai dengan diterbitkannya regulasi Wireless Power Transmission ini adalah perkembangan teknologi menuntut adanya harmonisasi aturan /undang-undang dalam penyelenggaraan Wireless Power Transmission dalam kehidupan sehari-hari. Kejelasan dan kepastian payung hukum fungsi pengaturan terhadap penyelenggaraan operasi bisnis Wireless Power Transmission.

Dampak positif yang ingin dicapai diantaranya Peningkatan industri dan investasi. Harmonisasi antara pemerintah, operator dan masyarakat Indonesia. Memberikan alternatif yang terintegrasi yaitu solusi regulasi pengaturan sumber daya sebelum dan sesudah regulasi dan diharapkan berbagai aplikasi TIK berdasarkan teknologi WPT akan aktif dipergunakan di masa depan.

\subsection{Impelementasi Wireless Power Transmission di Dunia}

Penggunaan Wireless Power Transmission sekarang sudah populer dan meluas berikut ini beberapa negara yang sudah mengimplementasikannya: 


\subsubsection{Korea}

Ketentuan mendefinisikan teknologi WPT, tingkat kekuatan medan dan frekuensi band yang dizinkan untuk peralatan WPT di Korea. Korea memberikan lebih rinci dan luas berbagai informasi dan respon dari ringkasan dibawah ini. Peralatan WPT lebih dari $50 \mathrm{~W}$ diklasifikasikan sebagai peralatan ISM dan membutuhkan lisensi untuk operasi. Tapi mereka yang dibawah $50 \mathrm{~W}$, "Registration of conformity" termasuk kekuatan medan listrik lemah dan pengujian EMC yang cukup untuk operasi.

EMC/EMI: CISPR-11 telah diterapkan untuk WPT, tetapi RRA merevisi peraturan yang relevan yang ada untuk mengklasifikasikan WPT sebagai perangkat rumah tanggga pada bulan juni 2013. Semua peralatan komunikasi radio termasuk perangkat WPT harus mematuhi tiga peraturan dibawah gelombang radio yaitu:

1. Regulasi teknis

2. Peraturan EMC

3. Peraturan EMF

Berikut ini penjelasan lebih lanjut mengenai regulasi teknis di Korea.PeralatanWPT diatur sebagai peralatan ISM dan peralatan lebih dari $50 \mathrm{~W}$ perlu lisensi untuk operasi. Untuk peralatan di bawah $50 \mathrm{~W}$, sesuai dengan ketentuan medan listrik lemah dan EMC pengujian regulasi teknis yang diperlukan. Baru-baru ini, pemerintah merevisi persyaratan kebutuhan dan karakteristik operasi sebagai berikut, dimana semua perangkat WPT diperlukan sebagai peralatan ISM

- Di kisaran $100-205 \mathrm{kHz}$, kekuatan medan listrik dari perangkat WPT kurang dari atau sama dengan $500 \mu \mathrm{V} / \mathrm{m}$ pada $3 \mathrm{~m}$. Nilai ini diperoleh oleh pedoman pengukuran disebut CISPR/I/417/PAS

- Di kisaran $6765-6795 \mathrm{kHz}$, kekuatan medan listrik harus puas sesuai dengan tabel dibawah ini.

- Di kisaran $19-21 \mathrm{kHz}, 59-61 \mathrm{kHz}$, kekuatan medan listrik kurang dari atau sama dengan $100 \mu \mathrm{V} / \mathrm{m}$ pada $100 \mathrm{~m}$.

Tabel 1 Batas kekuatan Medan yang diterapkan untuk WPT di Korea

\begin{tabular}{|c|c|c|c|}
\hline Frequency & Field Strength & $\begin{array}{l}\text { Pengukuran } \\
\text { Bandwidth }\end{array}$ & Jarak \\
\hline $9-150 \mathrm{kHz}$ & \multirow{2}{*}{$\begin{array}{l}\text { 78,5-10 log } \\
\text { (f di kHz/9) } \\
\mathrm{dB} \mu \mathrm{V} / \mathrm{m}\end{array}$} & $200 \mathrm{~Hz}$ & \multirow{5}{*}{$10 \mathrm{~m}$} \\
\hline $150-10 \mathrm{MHz}$ & & \multirow{2}{*}{$9 \mathrm{kHz}$} & \\
\hline $10-30 \mathrm{MHz}$ & $48 \mathrm{~dB} \mu \mathrm{V} / \mathrm{m}$ & & \\
\hline $30-230 \mathrm{MHz}$ & $30 \mathrm{~dB} \mu \mathrm{V} / \mathrm{m}$ & \multirow[b]{2}{*}{$120 \mathrm{kHz}$} & \\
\hline $230-1000 \mathrm{MHz}$ & $37 \mathrm{~dB} \mu \mathrm{V} / \mathrm{m}$ & & \\
\hline
\end{tabular}

Tabel 2 Regulasi yang di terapkan untuk WPT di Korea

\begin{tabular}{|l|l|l|l|}
\hline $\begin{array}{l}\text { Power } \\
\text { Level }\end{array}$ & Nama aplikasi & $\begin{array}{l}\text { Peraturan } \\
\text { Teknis } \\
\text { Aplikasi }\end{array}$ & $\begin{array}{l}\text { perijinan materi } \\
\text { dan teknologi WPT }\end{array}$ \\
\hline $\begin{array}{l}\text { Daya } \\
\text { rendah }(\leq 50\end{array}$ & $\begin{array}{l}\text { perangkat } \\
\text { ISM }- \text { WPT perangkat } \\
\text { menggunakan } \\
\text { rentang frekuensi } \\
100-205 \mathrm{kHz}\end{array}$ & $\begin{array}{l}\text { Weak Electric } \\
\text { Field } \\
\text { Strength }\end{array}$ & $\begin{array}{l}\text { produk komersial } \\
\text { menggunakan } \\
\text { teknologi induktif }\end{array}$ \\
\hline
\end{tabular}




\begin{tabular}{|l|l|l|l|}
\hline & $\begin{array}{l}\text { Peralatan ISM-WPT } \\
\text { perangkat } \\
\text { menggunakan } \\
\text { rentang frekuensi teknologi } \\
6765-6795\end{array}$ & ISM & $\begin{array}{l}\text { produk yang } \\
\text { menggunakan } \\
\text { teknologi resonansi }\end{array}$ \\
\hline $\begin{array}{l}\text { Daya } \\
\text { tinggi }\end{array}$ & $\begin{array}{l}\text { Peralatan ISM menggunakan } \\
\text { rentang frekuensi 19-21 } \\
\mathrm{kHz}, \text { 59-61 } \\
\mathrm{kHz}\end{array}$ & ISM & $\begin{array}{l}\text { dipasang pada area } \\
\text { spesifIK SMFIR } \\
\text { (Shaped Megnetic } \\
\text { Field } \\
\text { In Resonanc) }\end{array}$ \\
\hline
\end{tabular}

Sumber: Report ITU-R SM. 2303-0

\subsubsection{Jepang}

Di Jepang, Wireless Power Transmission Working Group dari Wireless Forum Broadband telah aktif pada banyak aspek dari promosi Wireless Power Transfer. Dalam regulasi di Jepang, perangkat dengan daya transmisi tidak melebihi $50 \mathrm{~W}$ tidak memerlukan izin oleh administrator untuk operasi pada umumnya. Saat ini teknologi yang diusulkan (b), (c) dan (d) pada tabel 3 beroperasi dengan daya tidak melebihi $50 \mathrm{~W}$ di setiap spektrum. Teknologi ini diharapkan dapat meningkatkan daya transmisi lebih besar dari $50 \mathrm{~W}$ di masa depan setelah selesai studi koeksistensi sukses dengan layanan komunikasi radio yang relevan.

Tabel 3 Teknologi WPT di Jepang

\begin{tabular}{|c|c|c|c|c|}
\hline $\begin{array}{l}\text { Target } \\
\text { Aplikasi } \\
\text { WPT }\end{array}$ & (A) WPT untuk Evs & $\begin{array}{l}\text { (B) WPT } \\
\text { untuk seluler } \\
\text { dan } \\
\text { perangkat } \\
\text { portable }\end{array}$ & $\begin{array}{l}\text { (C)WPT untuk } \\
\text { peralatan } \\
\text { rumah dan } \\
\text { peralatan } \\
\text { kantor } \\
\end{array}$ & $\begin{array}{l}\text { (D) WPT } \\
\text { untuk } \\
\text { seluler dan } \\
\text { perangkat } \\
\text { portable } \\
\end{array}$ \\
\hline $\begin{array}{l}\text { WPT } \\
\text { teknologi }\end{array}$ & \multicolumn{3}{|c|}{ transmisi listrik medan magnet } & $\begin{array}{l}\text { capacitive } \\
\text { coupling }\end{array}$ \\
\hline $\begin{array}{l}\text { Transmisi } \\
\text { Power }\end{array}$ & $\begin{array}{l}\text { hingga } 3 \mathrm{~kW} \\
(\text { Max } 7.7 \mathrm{~kW}\end{array}$ & $\begin{array}{l}\text { Beberapa W - } \\
100 \mathrm{~W}\end{array}$ & $\begin{array}{l}\text { Beberapa W - } \\
1,5 \mathrm{~kW}\end{array}$ & $100 \mathrm{~W}$ \\
\hline $\begin{array}{l}\text { Kandidat } \\
\text { Rentang } \\
\text { Frekuensi } \\
\mathrm{Wpt}\end{array}$ & $\begin{array}{l}42-48 \mathrm{kHz}(45 \mathrm{kHz} \text { band }) \\
52-58 \mathrm{kHz}(55 \mathrm{kHz} \text { band }) \\
79-90 \mathrm{kHz}(85 \mathrm{Khz} \text { band }) \\
140,91-148,5 \\
\mathrm{kHz}(145 \mathrm{kHz} \text { band })\end{array}$ & $\begin{array}{l}6765-6795 \\
\mathrm{kHz}\end{array}$ & $\begin{array}{l}20,05-38 \mathrm{kHz} \\
42-58 \mathrm{kHz} \\
62-100 \mathrm{kHz}\end{array}$ & $425-524 \mathrm{kHz}$ \\
\hline $\begin{array}{l}\text { Jarak } \\
\text { Transmisi }\end{array}$ & $0-30 \mathrm{~cm}$ & $0-30 \mathrm{~cm}$ & $0-10 \mathrm{~cm}$ & $1-1 \mathrm{~cm}$ \\
\hline
\end{tabular}

Sumber: Report ITU-R SM. 2303-0

Diantara banyak kegiatan yang di lakukan BWF, forum telah merilis dan memperbaharui "pedoman penggunaan teknologi transmisi daya nirkabel" edisi ke 2 yang dirilis pada tahun 2013. Pedoman ini juga memperkenalkan aturan yang relevan dan pemberitahuan dalam lampiran normatif. Pedoman ini berlaku untuk peralatan wireless power transfer memenuhi kondisi kinerja berikut:

- Daya transmisi tidak melebihi $50 \mathrm{~W}$

- Jarak transmisi listrik tidak melebihi beberapa meter

- Frekuensi transmisi: $10 \mathrm{kHz}$ sampai10 MHz, 13,56 MHz band (ISM band), 27,12 MHz (ISM band), dan 40,68 MHz (ISM band).

- Tidak ada batasan pada jenis peralatan yang digunakan atau metode transmisi listrik. 


\subsubsection{China}

Bagian ini memberikan klasifikasi dan analisis peraturan pada perangkat WPT di China saat ini, menurut definisi sistem regulasi berkaitan dengan perangkat WPT dan bagian komunikasi nirkabel, rentang frekuensi dan pembatasan perangkat radio yang berbeda.

\subsubsection{Klasifikasi dan analisis regulasi pada perangkat WPT.}

China tidak memiliki peraturan resmi WPT.Saat ini, hanya regulasi SRDmencakup semua pita frekuensi WPT. Oleh karena itu, dalam rangka untuk melindungi sistem komunikasi radio incumbent, perangkat WPT harus melalui tes masuk pasar yang sama dengan pintu masuk pasar uji SRD. Namun, hal ini tidak tepat untuk mengatur perangkat WPT sebagai SRD dalam jangka panjang. Oleh karena itu, klasifikasi dan regulasi penelitian WPT dilakukan sebagai berikut. Penelitian ini adalah pada awal fase, regulasi yang berbeda dan klasifikasi metode tidak di kecualikan.

\subsection{Perangkat ISM}

Dalam sistem regulasi radio China, perangkat ISM didefinisikan sebagai peralatan yang menggunakan energi RF untuk industri, ilmiah, medis, rumahtangga dan tujuan yang sama, yang tidak termasuk peralatan yang digunakan dalam telekomunikasi, teknologi informasi dan standar nasional lainnya. Perangkat WPT adalah peralatan yang digunakan dalam bidang industri rumah tangga atau menggunakan energi RF. Oleh karena itu, perangkat WPT dapat diletakkan dibawah perangkat ISM.

Menurut regulasi ISM China, perangkat ISM dibagi menjadi dua kelompok berdasarkan aplikasi mereka. Semua perangkat ISM yang memproduksi dan / atau menggunakan energi conductuvely coupled $R F$. Semua perangkat ISM, termasuk EDM dan peralatan yang memproduksi atau menggunakan energi elektromagnetik RF.

Menurut regulasi ISM China, dalam band pembatasan daya transmisi dari perangkat ISM bekerja di pita $6.675 \mathrm{MHz}-6.795 \mathrm{MHz}$ masih dalam pertimbangan. Radiasi palsu yang perlu memenuhi pembatasan gangguan radiasi elektromagnetik ditujukan pada Tabel 4.

Tabel 4. Pembatasan gangguan radiasi elektromagnetik dari kategori B kelompok 2 perangkat ISM

\begin{tabular}{|l|c|}
\hline \multicolumn{1}{|c|}{$\begin{array}{c}\text { Rentang } \\
\text { frekuensi }\end{array}$} & $\begin{array}{c}\text { Pembatasan gangguan kategori B } \\
\text { kelompok 2 perangkat } \\
\text { ISM / dB (v/m) (diukur pada 10 } \mathbf{~ m}\end{array}$ \\
\hline $0.15-3030-80.872$ & 30 \\
\hline 80.87281 .848 & 50 \\
\hline 81.848134 .768 & 30 \\
\hline 134.768136 .414 & 50 \\
\hline 136.414230 & 30 \\
\hline $230-1000$ & 37 \\
\hline
\end{tabular}

Berdasarkan analisis diatas, jika izin tersebut tersedia, perangkat WPT bekerja di pita 6.6756.795 MHz dapat diberikan sesuai dengan kategori B kelompok 2 perangkat ISM di China. Selain itu, WPT yang bekerja di pita frekuensi lain tidak dapat diberikan sesuai dengan perangkat ISM yang sesuai dengan radio regulasi di China saat ini.

\subsection{Short Range Device}

Dalam sistem regulasi radio China, SRD memilki 7 kategori dari kategori A sampai kategori G. Diantara mereka, band frekuensi bekerja dari kategori A ke D dibawah $30 \mathrm{MHz}$. Pita frekuensi 
dari kategori A adalah 9-190 kHz. Pita frekuensi dari kategori B dan band frekuensi WPT bekerja tidak tumpang tindih. Pita frekuensi dari kategori C meliputi 6.675-6.795 MHz. Kategori D, yang bekerja pada pita frekuensi $315 \mathrm{kHz}-30 \mathrm{MHz}$, termasuk SRD kecuali kategori A, kategori B dan kategori C. Oleh karena itu semua kerja WPT pita frekuensi kecuali190-205 kHz milik rentang frekuensi SRD. Selain itu, pita frekuensi dari perangkat WPT generasi pertama WPC adalah parsial lingkup luar pita frekuensi kategori A SRD ini. Oleh karena itu, dalam sudut pandang frekuensi, semua perangkat WPT berada di lingkup SRD kecuali perangkat WPT yang bekerja di $190-205$ $\mathrm{kHz}$.

Tidak ada definisi dari SRD dalam sistem radio regulasi China.Meskipun demikian, ada peraturan pemerintah didirikan untuk general micro-power (short range) peralatan transmisi radio. Transfer daya dari perangkat WPT tidak termasuk dalam kategori emisi radio. Sebagian besar listrik ditransmisikan ke penerima melalui kopling, induksi dan teknologi lainnya, bukan memancarkan energi ke ruang nirkabel. Oleh karena itu, dalam definisi perspektif, perangkat WPT tidak termasuk dalam ruang lingkup SRD.

Menurut regulasi nya, SRD harus memenuhi batas kekuatan magnet. Batas kekuatan magnet dari SRD kategori A, SRD kategori B, SRD kategori C ditunjukkan pada tabel 5.

Tabel 5. Batas kekuatan medan magnet dari SRD kategori A, SRD kategori B, SRD kategori C

\begin{tabular}{|l|l|l|}
\hline Kategori & $\begin{array}{l}\text { Pita Frekuensi yang sesua } \\
\text { perangkat WPT }\end{array}$ & $\begin{array}{l}\text { Pembatasan } \\
\text { Kekuatan medan } \\
\text { magnet }\end{array}$ \\
\hline $\begin{array}{l}\text { SRD } \\
\text { kategori A }\end{array}$ & $\begin{array}{l}\text { 9-190 kHz } \\
\text { Frekuensi band pertama } \\
\text { perangkat WPT } \\
\text { generasi WPC adalah parsial } \\
\text { lingkup luar } \\
\text { pita frekuensi SRD kategori A ini }\end{array}$ & $72 \mathrm{~dB} \mu \mathrm{A} / \mathrm{m}$ \\
\hline $\begin{array}{l}\text { SRD } \\
\text { kategori B }\end{array}$ & $6765-6795 \mathrm{kHz}$ & $42 \mathrm{~dB} \mu \mathrm{A} / \mathrm{m}$ \\
\hline $\begin{array}{l}\text { SRD } \\
\text { kategori C }\end{array}$ & $425-524 \mathrm{kHz}$ & $5 \mathrm{~dB} \mu \mathrm{A} / \mathrm{m}$ \\
\hline
\end{tabular}

\subsubsection{Singapura}

Short Range Device di Singapura harus dirancang untuk memenuhi tujuan untuk beroperasi terlindungi dan berbagi pita frekuensi. Operasi yang tidak akan menyebabkan gangguan layanan komunikasi radio lainnya yang berwenang dan dapat mentolerir gangguan yang disebabkan oleh layanan komunikasi radio lainnya, peralatan listrik atau elektronik.

Perangkat tidak akan dibangun dengan kontrol eksternal yang mudah atau mudah di akses yang memungkinkan penyesuaian operasinya dengan cara yang tidak sesuai dengan spesifikasinya.

Untuk penilaian EMC SRD atau tambahan peralatan harus diklasifikasikan sebagai peralatan untuk digunakan tetap; penggunaan kendaraan (yaitu terminal mobile terhubung dengan charger kendaraan atau pasokan DC); atau penggunaan mobile portable (yaitu didukung oleh baterai terpisahnya).

\subsection{Main Standar Interface WPT dan Aliansi}

Meskipun industri WPT sangat muda, standar "perang" telah dimulai dengan 3 aliansi utama yang bersaing: WPC, A4WP dan PMA. Selain itu, setiap aliansi mendorong sendiri kompleks serta kompatibel nya teknologi, spesifikasi dan desain. Oleh karena itu, dibutuhkan suatu standar global 
yang umum (seperti yang dilakukan dengan Wi-Fi) untuk memastikan kelebihan semua kompatibilitas produk, menurunkan biaya dan memperluas inovasi. Ringkasan Standar Interface WPT dan Aliansi pada Januari 2015

Tabel. 6 Ringkasan Standar Interface WPT dan Aliansi pada Januari 2015

\begin{tabular}{|l|l|l|l|}
\hline Organization & WPC & PMA & A4WP \\
\hline Established & 2008 & 2012 & 2012 \\
\hline Jumlah anggota & $203+$ & $80+$ & $140+$ \\
\hline $\begin{array}{l}\text { Transfer } \\
\text { tipe }\end{array}$ & Inductive Coupling & $\begin{array}{l}\text { Inductive } \\
\text { Coupling }\end{array}$ & $\begin{array}{l}\text { Magnetic } \\
\text { resonance }\end{array}$ \\
\hline Max. Transfer Power & $5 \mathrm{~W}(10-15 \mathrm{~W}$ soon $)$ & $5 \mathrm{~W}(10-15 \mathrm{~W}$ soon $)$ & hingga 50W \\
\hline Jarak & jarak pendek & jarak pendek & jarak mnengah \\
\hline Frekuensi Transfer & $100-205 \mathrm{kHz}$ & $277-357 \mathrm{kHz}$ & $6.78 \mathrm{MHz}$ \\
\hline Versi Terbaru & $1,1,2$ & PMA1.1 & A4WP-s-0001 v1.2 \\
\hline Produk Bersertifikt & 684 & 24 & 2 \\
\hline $\begin{array}{l}\text { Laboratorium Penguji } \\
\text { Resmi }\end{array}$ & 10 & 3 & \\
\hline
\end{tabular}

Pada CES 2015, Aliansi untuk Wireless Power (A4WP) dan PMA mengumumkan bahwa mereka telah sepakat untuk bergabung menjadi satu organisasi dengan maksud untuk membuat standar terpadu, yang sudah dikritik oleh perwakilan WPC. Rupanya ada tren positif terhadap standar WPT global, meskipun sekarang standar "perang" akan terus antara A4WP + PMA dan WPC.

\subsection{Hasil Benchmark di 5 Negara}

Di China perangkat WPT bekerja dalam band $6,675-6,795 \mathrm{MHz}$ dapatdiberikan sesuai dengan kategori B kelompok 2 perangkat ISM, dan perangkat WPT yang bekerja di band lainnya dapat diberikan sesuai dengan SRD temporal. Dalam jangka panjang, perlu untuk megalokasikan pita frekuensi WPT sesegera mungkin dan merumuskan spesfikasi teknis EMC dari perangkat WPT.

Di Singapura perangkat WPT yang bekerja dalam band $6765-6795 \mathrm{kHz}$ dengan maximum field strength $/ \mathrm{RF}$ output power $=42 \mathrm{~dB} \mu \mathrm{A} / \mathrm{m} @ 10 \mathrm{~m}$ merupakan perangkat Short Range Device (SRD) yang tidak memerlukan persetujuan IDA untuk operasi tetap, sedanngkan mereka yang memerlukan persetujuan IDA untuk operasi adalah:

1. Maximum field strength / RF output power $=1000 \mathrm{~mW}$ (erp)

- $170.275 \mathrm{MHz}$

- $170.375 \mathrm{MHz}$

- $173.575 \mathrm{MHz}$

- $173.675 \mathrm{MHz}$

- $451.750 \mathrm{MHz}$

- $452.000 \mathrm{MHz}$

- $452.050 \mathrm{MHz}$

- $452.325 \mathrm{MHz}$

2. Maximum field strength / RF output power $>500 \mathrm{~mW}$ (erp)

- $26.96-27.28 \mathrm{MHz}$

3. Maximum field strength / RF output power $\leq 3000 \mathrm{~mW}$ (erp)

- $40.66-40.70 \mathrm{MHz}$

4. Maximum field strength / RF output power $>1000 \mathrm{~mW}$ (erp)

- $151.125 \mathrm{MHz}$ 
5. Maximum field strength / RF output power $\leq 3000 \mathrm{~mW}$ (erp)

- $151.150 \mathrm{MHz}$

6. Maximum field strength / RF output power $>1000 \mathrm{~mW}$ (erp) $\leq 2000 \mathrm{~mW}$ (erp)

- $920-925 \mathrm{MHz}$

7. Maximum field strength / RF output power $>1000 \mathrm{~mW}$ (erp) $\leq 4000 \mathrm{~mW}$ (erp)

- $5.725-5850 \mathrm{MHz}$

Di Indonesia setiap alat dan perangkat telekomunikasi jarak dekat (short range devices) yang dibuat, dirakit, dimasukkan untuk diperdagangkan dan / atau digunakan di Wilayah Negara Indonesia wajib memenuhi persyaratan teknis sebagaimana tercantum dalam tabel di bawah ini, penilaian terhadap kewajiban setiap alat dan perangkat telekomunikasi jarak dekat memenuhi persyaratan teknis sebagaimana disebut diatas harus melalui pengujian sesuai ketentuan peraturan perundang-undangan.

Alat dan perangkat telekomunikasi jarak dekat (short range devices) yang selanjutnya disingkat SRD adalah pemancar dan atau penerima berdaya pancar rendah yang menyediakan komunikasi radio jarak dekat untuk aplikasi tetap dan bergerak pada pita frekuensi radio tertentu dan dalam penggunaan frekuensi radionya tidak mendapatkan perlindungan serta tidak boleh menimbulkan gangguan yang merugikan (harmful interference).

Setiap SRD wajib memiliki karakteristik utama sebagai berikut:

1. Catu daya (power supply): $220 \mathrm{VAC}$ atau baterai

2. Kesesuaian elektromagnetik (Electromagnetic Compatibility) mengacu pada rekomendasi CISPR 22 dan CISPR 24 atau yang setara

3. Hanya beroperasi pada pita frekuensi radio yang ditentukan, serta menggunakan kuat medan (ERP) maksimum dan batasan teknis sebagaiamana dimaksud dalam tabel dibawah ini:

Tabel 8 SRD di Indonesia

\begin{tabular}{|c|c|c|}
\hline Pita Frekuensi & $\begin{array}{l}\text { Kuat medan / ERP } \\
\text { maksimum }\end{array}$ & Contoh Aplikasi SRD \\
\hline $16 \mathrm{kHz}-150 \mathrm{kHz}$ & $\begin{array}{l}\leq 100 \mathrm{~dB} \mu \mathrm{V} / \mathrm{m} \text { pada jarak } \\
3 \mathrm{~m}\end{array}$ & $\begin{array}{l}\text { sistem aliran induksi (Induction loop system). } \\
\text { untuk alat bantu dengar (hearingaid) atau alat } \\
\text { bantu dengar suara agar lebih jernih (loop } \\
\text { listener hear sounds) }\end{array}$ \\
\hline $510 \mathrm{kHz}-1600 \mathrm{kHz}$ & $\begin{array}{l}\leq 57 \mathrm{~dB} \mu \mathrm{V} / \mathrm{m} \text { pada jarak } \\
3 \mathrm{~m}\end{array}$ & mikrofon nirkabel (wireless microphone) \\
\hline $6765 \mathrm{kHz}-6795 \mathrm{kHz}$ & $\leq 57100 \mathrm{~mW}$ ERP & $\begin{array}{l}\text { untuk aplikasi Industrial Scientific and } \\
\text { Medical) }\end{array}$ \\
\hline
\end{tabular}

Di Indonesia selain menggunakan Peraturan Menteri Komunikasi dan Informatika RI No. 35 Tahun 2015 tentang persyaratan teknis alat dan perangkat telekomunikasi jarak dekat. Untuk WPT ini bisa juga menggunakan Peraturan Direktur Jenderal Pos dan Telekomunikasi No. 214/DIRJEN/2005 tentang Persyaratan Teknis Alat dan Perangkat dengan Daya Pancar di Bawah $10 \mathrm{~mW}$.

Yang dimaksud dengan alat dan perangkat dengan daya pancar dibawah $10 \mathrm{~mW}$ adalah alat dan perangkat yang menggunakan pemancar radio dengan daya pancar rendah (low power) dan bekerja dengan menggunakan daya pancar tidak melebihi $10 \mathrm{~mW}$ dengan karakteristik utama sebagaimana pada tabel dibawah ini. 
Tabel 9 Karakteristik alat dan peralatan dengan daya pancar dibawah $10 \mathrm{~mW}$

\begin{tabular}{|l|l|l|}
\hline Frekuensi (MHz) & $\begin{array}{l}\text { Field Strength } \\
\text { (microvolts/meter) }\end{array}$ & $\begin{array}{l}\text { Jarak Pengukuran } \\
\text { (meters) }\end{array}$ \\
\hline $0.009-0.450$ & 100 & 3 \\
\hline $0.450-1.705$ & 57 & 3 \\
\hline $1.705-13.567$ & 94 & 10 \\
\hline $13.567-30.0$ & 65 & 10 \\
\hline $30-88$ & 100 & 3 \\
\hline $88-216$ & 150 & 3 \\
\hline $216-960$ & 200 & 3 \\
\hline diatas 960 & 500 & 3 \\
\hline
\end{tabular}

Aplikasi alat dan perangkat dimaksud antara lain: alarms, identification systems, radiodetection, vehicle radar systems, wireless local area networks, remote controls, telecommand, telemetry, on-site paging systems, cordless keyboard, vehicle keyless entry dan lain-lain. Alat dan perangkat dimaksud hanya digunakan untuk komunikasi di dalam gedung atau beroperasi di lokasi terbatas dan beroperasi bersama dalam suatu range frekuensi dan didalam pengoperasiannya tidak menyebabkan interferensi terhadap perangkat komunikasi radio lain, dan siap menerima interferensi yang disebabkan oleh komunikasi radio, elektrik atau peralatan elektronik lain.

\section{KESIMPULAN}

Dari studi saat ini bahwa regulasi tidak begitu jelas ditentukan, standardisasi dan regulasi merupakan aspek yang sangat penting untuk proliferasi masa depan Wireless Power Transmission. Jepang dan Korea telah memiliki rentang frekuensi untuk WPT dan membawa mereka ke pertimbangan regulasi teknis, sedangkan China dan Singapura masih mempelajari teknologi yang terkait dengan WPT

Dari tulisan ini kita dapat melihat regulasi diatas belum terwakili semua nya sehingga perlu dibuat regulasi yang spesifik mengenai Wireless Power Transmission di Indonesia. Indonesia diharapkan memberikan lebih rinci dan luas berbagai informasi dari peralatan WPT lebih dari $50 \mathrm{~W}$ diklasifikasikan sebagai peralatan ISM dan membutuhkan lisensi untuk operasi. Tapi mereka yang dibawah $50 \mathrm{~W}$, "Registration of conformity" termasuk kekuatan medan listrik lemah dan pengujian EMC yang cukup untuk operasi. Dengan demikian peluang penelitian lain yang dapat dilakukan diantaranya dengan melakukan dari sisi teknis untuk penerapan di Indonesia.

\section{DAFTAR PUSTAKA}

- Jurnal

Anthony, Richard N. Navgahre, Seema P. (2016). Introduction To Wireless Power Transfer. International Journal of Scientific Engineering and Appliied Science (IJSEAS)-Volume 2.

- Buku

Spectrum Management Handbook. (2016). Indocom Media Development Authority. Singapore.

\section{- Tesis/Disertasi}

Vladislav, Khayrudinov. (2015). Wireless Power Transfer System Development and Implementation. Thesis. Bachelor of Engineering, Helsinki Metrople University.

Amirudin. (2017). Analisis Perspektif Regulasi Dynamic Wireless Power Transmission. Pascasarjana, Universitas Mercu Buana. 


\section{- Internet}

Christos, Kalialakis. Borges, Carvalho Nuno. Shinohara, Naoki. (2016), Development in Wireless Power Transfer Standards and Regulatios

Draft APT New Report on Wireless Power Transmission. 9-13 March 2015. Asia-Pasific Telecomunity. The $18^{\text {th }}$ Meet of APT Wireless Group. Kyoto-Japan

Interntional Telecommunications Union (ITU). Report ITU-R SM. 2303-0. (2014). Wireless Power Transmission Using Technologies Other Than Radio Frequency Beam.

Interntional Telecommunications Union (ITU). Report ITU-R SM. 2303-1. (2015). Wireless Power Transmission Using Technologies Other Than Radio Frequency Beam.

Interntional Telecommunications Union (ITU). Report ITU-R SM. 2392-0. (2016). Aplications of Wireless Power Transmission Radio Frequency Beam.

Peraturan Menteri Komunikasi dan Informatika Republika Indonesia Nomor 35 Tahun 2015tentang persyaratan teknis alat dan perangkat telekomunikasijarak dekat.

Peraturan Direktur Jenderal Pos dan Telekomunikasi Nomor :214/DIRJEN/2005 tentang Persyaratan teknis alat dan perangkat dengan daya pancar dibawah $10 \mathrm{~mW}$.

Setiawan, Denny. (2010) Alokasi Frekuensi Kebijakan dan perencanaan spektrum di Indonesia. Departemen Komunikasi dan Informatika. Direktorat Jenderal Pos dan Telekomunikasi.

Xiao, Lu. Ping, Wang. Dusit, Niyato. Kim, Dong In. Zhu, Han. (2015), Wireless Charging Technologies: Fundamentals, Standards, and Network Applications. Department of Electrical and Computer Engineering, Nanyang Technological University, Singapore., School of Information and Communication Engineering, Sungkyunkwan University (SKKU), Korea., Electrical and Compter Engineering, University of Houston, Texas, USA. 